\title{
El cardenal Bonel y Orbe (1782-1857), obispo y parlamentario. Un acercamiento a su biografía
}

Cardinal Bonely Orbe (1782-1857), bishop and parliamentarian. An approach to his biography

Gonzalo BARBED MARTÍN

Diócesis de Madrid

C/Villasilos 3, 28017 Madrid

https://orcid.org/0000-0001-5085-386X

gbarbed@gmail.com

Abstract: Our knowledge of the Spanish Church during the 19th Century has advanced considerably through the publication of some prominent bishops' biographies. However, many of these figures are still unfamiliar to us. This is the case with Juan José Bonel y Orbe (1782-1857), a distinguished prelate during the difficult years of Isabel II's regencies and the beginnings of moderate politics. Bishop of Málaga and Córdoba and later primate of Toledo and cardinal, he gave many speeches as a senator, as well as being the Queen's confessor. This article provides an approach to his biography on the basis of the published sources available, with the objective of shedding light on his historical importance.

Keywords: Juan José Bonel y Orbe; bishops' biographies; liberal revolution; liberal bishops; parliamentarian bishops.
Resumen: Nuestro conocimiento de la Iglesia española del siglo XIX ha avanzado considerablemente gracias al estudio de algunas biografías de obispos destacados. Sin embargo, aún muchos nos son casi enteramente desconocidos. Este es el caso de Juan José Bonel y Orbe (1782-1857), un importante prelado en los difíciles años de las regencias isabelinas y los comienzos del moderantismo. Obispo de Málaga y Córdoba y más tarde primado de Toledo y cardenal, fue un senador prolífico en discursos, además de confesor de Isabel II. Este artículo pretende realizar un acercamiento a su biografía a partir de las fuentes editadas disponibles, con el objeto de mostrar su relevancia histórica.

Palabras clave: Juan José Bonel y Orbe; biografías de obispos; revolución liberal; obispos liberales; obispos parlamentarios.

\section{INTRODUCCIÓN}

El conocimiento de la historia de la Iglesia española contemporánea ha avanzado considerablemente en los últimos decenios gracias en buena medida al interés creciente suscitado por las biografías de los eclesiásticos más relevantes. La vida, la actividad y el pensamiento de estos personajes suponen un modo de acceso privilegiado y fundamental para introducirse en los grandes problemas que plan- 
tea la situación de la Iglesia en el mundo. De este modo, se construye una microbistoria que, aunque desde una perspectiva particular y parcial, ayuda sin duda a profundizar y completar la macro-bistoria global. Este interés ha llevado a conocer más a fondo las vidas y aportaciones de muchos obispos españoles a través de sus actuaciones concretas en las situaciones, a menudo tan extraordinarias, del siglo XIX. De este modo, ha permitido ir más allá de algunas categorías generales repetidas por la historiografía, como por ejemplo el rígido binomio liberal-reaccionario. También se han puesto de relieve figuras importantes del episcopado nacional a las que no se les había prestado la suficiente atención, por las que se va conociendo cada vez más la Iglesia decimonónica, especialmente en la segunda mitad de siglo ${ }^{1}$.

A pesar de todo, esta labor está muy lejos de quedar concluida satisfactoriamente. Así se ve en el caso de Juan José Bonel y Orbe (1782-1857), un obispo tan relevante como desconocido, que ha suscitado muy poco interés en la historiografía reciente. Esta carencia contrasta con los estudios que han procurado resaltar la figura de su antecesor en la sede toledana, el cardenal Inguanzo ${ }^{2}$, así como de otros de sus sucesores de décadas posteriores ${ }^{3}$.

Tres datos permiten valorar la importancia de Bonel y Orbe como figura sobresaliente de la Iglesia en la transición del antiguo al nuevo régimen. Fue, durante los años decisivos de la minoría de edad de Isabel II y de la década moderada, obispo de Málaga y Córdoba, arzobispo de Toledo (por tanto, primado de España) y más tarde cardenal, con una fulgurante carrera eclesiástica, social y académica. Además, mantuvo el cargo político de senador casi interrumpidamen-

1 Sirvan sólo de ejemplo: Franco DÍAZ DE CERIO, Un cardenal, filósofo de la historia. Fr. Zeferino González, O.P. (1831-1894), Roma, 1969; Julián BARRIO BARRIO, Félix Torres Amat (1772-1847), Burgos, 1978; Rafael María SANZ DE DIEGO, Medio siglo de relaciones Iglesia-estado. El cardenal Antolín Monescillo y Viso (1811-1897), Madrid, 1979; Vito-Tomás GÓMEZ GARCÍA, El cardenal fr. Manuel García y Gil, O. P. Obispo de Badajoz y arzobispo de Zaragoza (1802-1881), Valencia, 1990; Santiago CASAS RABASA, En el bicentenario del nacimiento de don Fosé Caixal y Estradé, obispo de Urgel, en Analecta sacra tarraconensia, 76 (2003), pp. 257-288; Francisco José GUERRERO CAROT, Un cruzado contra el Liberalismo. Aguilar y Serrat (Manlleu 1826-Segorbe 1899), obispo de Segorbe, Segorbe, 2013; Francesc ClOSA SALINAS, El obispo Pedro Cirilo Úriz y Labayru en la encrucijada del concordato de 1851, en Hispania sacra, 67 (2015), pp. 673-715.

2 Melchor DE Pobladura, Semblanza del cardenal Pedro de Inguanzo, Arzobispo de Toledo. Escrita por 7. Fernández Cortina, en Hispania Sacra, 5 (1958), pp. 327-338; José Manuel CuenCA TORIBIO, D. Pedro de Iguanzo y Rivero, último Primado del Antiguo Régimen, Pamplona, 1965; Manuel GUTIÉRREZ GARCÍA-BRAZALES, El cardenal Inguanzo (1824-1836), en Cuadernos de historia contemporánea, 13 (1991), pp. 9-24.

3 Franco Díaz DE Cerio, El Cardenal Ceferino González, O. P. (1831-1894), en Pensamiento, 20 (1964), pp. 27-70; Rafael María SANZ DE DIEGO, Medio siglo... [ver n. 1]. 
te entre 1835 y 1853 , siendo en su tiempo el prelado más prolífico en discursos parlamentarios, muchos de los cuales fueron rápidamente publicados y suscitaron gran interés. Por último, tuvo un papel decisivo en la propia corte de Isabel II, siendo elegido como su confesor real durante casi veinte años. Sin embargo, estas tres notas, que a priori situarían al obispo como uno de los prelados más importante de mediados del siglo XIX, contrastan con la imagen que de él ha transmitido la historiografía, manifestando un gran desconocimiento de su biografía. La gran mayoría de los historiadores lo describen como una figura secundaria y gris del grupo del episcopado liberal y colaboracionista, dócil a los proyectos de los gobiernos liberales.

\section{FUENTES PARA LA BIOGRAFÍA DE UN OBISPO DEL SIGLO XIX}

En la tarea de aproximarnos a la biografía de Juan José Bonel y Orbe, partimos de la base de un gran desconocimiento de las figuras del episcopado español decimonónico, tanto en su labor pastoral como en su presencia social. Los estudios con frecuencia son excesivamente sintéticos, superficiales y generales,

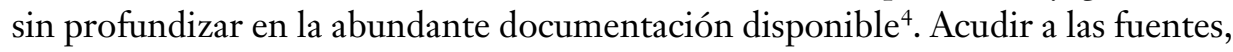
por tanto, es el camino único y obligado para profundizar en la vida de uno de los prelados más relevantes del siglo XIX español. Con este objetivo, vamos a indicar a continuación un catálogo fundamental de fuentes que nos pueden ayudar en esta tarea ${ }^{5}$.

\section{Catálogo de obras publicadas de Bonel y Orbe}

En primer lugar, es imprescindible realizar un elenco lo más completo posible de los escritos de Juan José Bonel y Orbe. Todavía no se ha encontrado

4 Así lo reconoce Vicente CÁRCEL ORTÍ, El liberalismo en el poder (1833-1868), en Ricardo GARCÍAVilloslada y Vicente CÁrCEl ORTí (dirs.), Historia de la Iglesia en España, t. 5, Madrid, 1979, p. 174: «Los obispos españoles del siglo XIX siguen siendo en gran parte desconocidos, aunque crecen por días las aportaciones parciales que ayudarán a descubrir la verdadera figura del prelado decimonónico español y su presencia en la sociedad. La documentación inédita es inmensa. [...] Entre tanto, por desgracia, se vive de generalidades, de estudios superficiales, que ignoran los archivos, y de apresuradas síntesis carentes de base documental sólida».

5 Para una mejor comprensión, seguimos un esquema similar al que se emplea en el estudio preliminar de Rafael María SANZ DE DIEGO, Medio siglo... [ver n. 1], pp. XXIII-LXXXI. 
ninguna relación de sus obras completas; a lo sumo, en las breves reseñas biográficas se indican algunas de sus producciones más sobresalientes. Por ello, en este apartado pretendemos consignar todos aquellos escritos suyos que se hallan publicados y que hemos podido descubrir. Aunque esta enumeración no pretende ser exhaustiva, sí creemos que recoge en buen medida sus contribuciones más destacadas, lo cual nos permite hacernos una idea del volumen y el tipo de su producción escrita ${ }^{6}$.

a) Recopilaciones de sus principales obras

- BONEL y ORBE, Juan José, Discursos del señor Don fuan Fosé Bonel y Orbe, Madrid, 1839-1852.

- Discursos del Excmo. e Ilmo. Señor Don Fuan Fosé Bonel y Orbe, 1782-1857, Madrid, 1839-1855.

b) Cartas y edictos pastorales ${ }^{7}$

- Auto de erección de cinco nuevas parroquias filiales en la ciudad de Málaga, Málaga, 1831.

- Tabla del jubileo circular de las cuarenta horas para los pueblos e iglesias de la diócesis de Málaga, Málaga, 1833.

- Circular del Obispo de Córdoba sobre las preces que se habian de hacer en su diócesis por la muerte de Gregorio XVI y elección de sucesor, Madrid, 1846 (12-6-1846).

- Carta pastoral del Excmo. é Ilmo. señor don Fuan Fosé Bonel y Orbe, Obispo de Córdoba, preconizado Arzobispo de Toledo al clero y fieles de la diócesis despidiéndose de sus diocesanos por haber sido nombrado arzobispo de Toledo, Madrid, 1847 (1-11-1847).

- Edicto pastoral del Emmo. Señor D. Juan Fosé Bonel y Orbe, Arzobispo de Toledo, Primado de las Españas, para la rogativa pública por N. Smo. Padre Pío IX, Madrid, 1848 (6-12-1848).

- Carta pastoral del Excmo. e Ilmo. Señor D. Juan Fosé Bonel y Orbe, Arzobispo de Toledo, Primado de las Españas, y encíclica de N. SS. Padre Pío IX para la rogativa pública por la definición dogmática del Misterio de la Inmaculada Concepción de Nuestra Señora, Madrid, 1849 (25-4-1849). Incluye la encíclica del papa Pío IX Ubi primum (2-2-1849).

6 Se seguirá un orden temático según el género de los escritos; y dentro de cada apartado se detallan las obras por orden cronológico. Con respecto a los títulos, se ha procurado respetar el de la edición impresa. Sólo en caso de no haberlo se designará con el incipit del texto.

7 Indicamos entre paréntesis la fecha oficial de publicación del texto. 
- Carta pastoral del Emmo. y Excmo. Señor Cardenal Arzobispo de Toledo, Primado de las Españas, al clero y fieles de su diócesis, al publicar la Indulgencia plenísima en forma de Fubileo, concedida por Nstro. Smo. P. Pí IX en el año de 1850, Madrid, 1851 (24-9-1851).

- Carta pastoral del Emmo. Señor D. Fuan Fosé Bonel y Orbe presbitero Cardenal de la Santa Romana Iglesia, Arzobispo de Toledo, Primado de las Españas, para establecer en su diócesis la obra de la Santa Infancia o Asociación de los niños y niñas cristianos para el rescate de los niños y niñas infieles de la China y de los demás países idólatras, Madrid, 1853 (16-1-1853).

- Carta pastoral, exhortando a sus diocesanos para que socorran con sus limosnas a los necesitados de Galicia, Madrid, 1853 (18-6-1853).

- Carta pastoral del Emmo. Señor D. Fuan Fosé Bonel y Orbe, presbitero Cardenal de la Santa Romana Iglesia, Arzobispo de Toledo, Primado de las Españas, exhortando a sus diocesanos para que se abstengan de las diversiones y experiencias de las mesas llamadas giratorias y parlantes, Madrid, 1854 (19-2-1854).

- Carta pastoral del Emmo. y Excmo. Señor Cardenal Arzobispo de Toledo, Primado de las Españas, al clero y fieles de su diócesis, al publicar la Indulgencia plenísima en forma de fubileo, concedida por Nstro. Smo. P. Pí IX en su Encíclica de 1. ${ }^{\circ}$ de Agosto de 1854, Toledo, 1854 (6-11-1854). Incluyendo la encíclica del papa Pío IX (1-8-1854).

- Carta pastoral de D. Juan Fosé Bonel y Orbe para la rogativa pública por la calamidad del cólera-morbo asiático, Toledo, 1855 (25-7-1855)

c) Discursos parlamentarios publicados

- Discursos pronunciados en el Senado por los señores Duque de Rivas, Marqués del Miraflores y Obispo de Córdoba en las sesiones de los días $1^{\circ}$ y $2^{\circ}$ de marzo de 1838 , Madrid, 1838.

- Discursos del Señor Don Juan Fosé Bonel y Orbe, Obispo de Córdoba, pronunciados en las sesiones del Estamento de Próceres de 4 de octubre y 15 de diciembre de 1834, 23 de mayo de 1835 y 18 de abril de 1836, y en la del Senado de 2 de marzo de 1838, sobre Asuntos Eclesiásticos, Madrid, 1839.

- Discursos del Señor Don fuan Fosé Bonel y Orbe, Obispo de Córdoba, en las sesiones del Senado de 23 y 25 de junio y 13 de julio de 1838, sobre Diezmos y dotación del Culto y Clero, Madrid, 1839.

- Discurso del Señor Don Fuan Fosé Bonel y Orbe, Obispo de Córdoba, pronunciado en las sesiones del Senado de 4 y 6 de julio de 1840, sobre el proyecto de la ley de dotación del Culto y Clero, Madrid, 1840. 
- Discursos del Señor Don Zuan José Bonel y Orbe, Obispo de Córdoba, pronunciados en las sesiones del Senado de 2, 4, 7, 16, 20 y 21 de agosto de 1841 sobre los proyectos de ley de dotación de Culto y Clero; adjudicación de bienes de Capellanías colativas de familias como de libre disposición a los parientes que tengan derecho; y enajenación de los bienes del clero secular, Madrid, 1841.

- Discursos del Señor Don Juan Fosé Bonel y Orbe, Obispo de Córdoba, pronunciados en las sesiones del Senado 26 de abril, 13 y 19 de mayo de 1843 sobre confirmación de Obispos y Supremacía del Romano Pontífice, y apoyo a la adición presentada por el mismo relativa al Culto y Clero, y del informe de la Comisión, Madrid, 1843.

- Discurso del Señor Don Juan Fosé Bonel y Orbe, Obispo de Córdoba, pronunciado en la sesión del Senado de 22 de enero de 1847, sobre la independencia de la dotación del culto y clero, Madrid, 1847.

- Discurso del Emmo. señor D. Fuan Fosé Bonel y Orbe, cardenal de la Santa Romana Iglesia, arzobispo de Toledo, pronunciado en la sesión del Senado de 18 de marzo de 1848, sobre el Proyecto de Ley para la provisión de prebendas y beneficios eclesiásticos, Madrid, 1852.

- Dictamen sobre el proyecto de ley para la provisión de prebendas y beneficios eclesiásticos, Madrid, 1852.

d) Todos sus discursos parlamentarios en los Diarios de las sesiones de Cortes ${ }^{8}$

- Discurso sobre el voto a Santiago: DSC 1834-35, 18-9-1834, n. 18, p. 191.

- Discurso sobre el voto a Santiago: DSC 1834-35, 4-10-1834, n. 19, pp. 199-202.

- Discurso sobre la exención de los clérigos de la Milicia urbana: DSC 1834-35, 15-121834, n. 30, pp. 274-275.

- Discurso sobre los presupuestos de la Casa Real: DSC 1834-35, 20-5-1835, n. 54, p. 445.

- Discurso sobre el presupuesto de clero y las rentas decimales: DSC 1834-35, 23-51835, n. 57, pp. 526-529.

- Discurso sobre la supresión de los institutos religiosos: DSC 1836, 18-4-1836, n. 6, pp. 25-28.

- Discurso sobre los bienes de las religiosas: DSC 1837-38, t. 1, 2-3-1838, n. 45, pp. 433-435.

- Discurso sobre la continuación del diezmo: DSC 1837-38, t. 2, 23-6-1838, n. 78, pp. 900-910.

8 En esta enumeración de los Diarios de las Sesiones de Cortes [DSC], los títulos son míos, atendiendo a su temática principal. 
- Discurso sobre la continuación del diezmo: DSC 1837-38, t. 2, 25-6-1838, n. 79, pp. 922-923.

- Discurso sobre la dotación de culto y clero: DSC 1837-38, t. 2, 13-7-1838, n. 91, pp. 1122-1126.

- Discurso sobre la necesidad de mantener el orden de la nación: DSC 1838-89, 30-111838, n. 10, p. 90.

- Discurso sobre el diezmo y el arreglo de culto y clero: DSC 1840, t. 2, 4-7-1840, n. 65, pp. 1103-1111.

- Discurso sobre el diezmo y el arreglo de culto y clero: DSC 1840, t. 2, 6-7-1840, n. 66, pp. 1122-1127.

- Discurso sobre la tutela de la reina Isabel II y la infanta Luisa Fernanda: DSC 1841, t. 1, 1-7-1841, n. 39, pp. 461-466.

- Discurso sobre la dotación de culto y clero: DSC 1841, t. 2, 2-8-1841, n. 61, pp. 774-785.

- Discurso sobre la dotación de culto y clero: DSC 1841, t. 2, 3-8-1841, n. 62, p. 805.

- Discurso sobre la dotación de culto y clero: DSC 1841, t. 2, 4-8-1841, n. 63, pp. 829831 y 834 .

- Discurso sobre la dotación de culto y clero: DSC 184, t. 2, 7-8-1841, n. 66, pp. 902-910.

- Discurso sobre las capellanías colativas: DSC 1841, t. 2, 16-8-1841, n. 71, pp. 10131014; 1016-1017 y 1022.

- Discurso sobre la enajenación de bienes del clero secular: DSC 1841, t. 2, 20-8-1841 noche, n. 76, pp. 1160-1165 y 1169-1170.

- Discurso sobre la enajenación de bienes del clero secular: DSC 1841, t. 2, 21-8-1841, n. 77, p. 1183.

- Discurso sobre la enajenación de bienes del clero secular: DSC 1841, t. 2, 21-8-1841 noche, n. 78, pp. 1196-97.

- Discurso sobre la ruptura de relaciones con Roma: DSC 1843/2a , 26-4-1843, n. 17, pp. 170-174.

- Discurso sobre la situación del culto y clero: DSC 1843/2a, 13-5-1843, n. 31, pp. 421-427.

- Discurso sobre los exclaustrados: DSC $1843 / 2^{a}, 19-5-1843$, n. 35 , pp. 494-495.

- Discurso sobre la independencia de la dotación del culto y clero: DSC 1846-47, 22-11847, n. 14, pp. 155-160.

- Discurso sobre los Vicarios enviados por el Papa: DSC 1847-48, 13-12-1847, n. 14, p. 208.

- Discurso sobre rectificación al acta del 13-12-1847: DSC 1847-48, 14-12-1847, n. 15, p. 228.

- Discurso sobre la provisión de prebendas eclesiásticas: DSC 1847-48, 3-1-1848, n. 21, pp. 311-312. 
- Discurso sobre el Código penal: DSC 1847-48, 16-2-1848, n. 32, pp. 505-509.

- Discurso sobre una exposición del cabildo de Toledo: DSC 1847-48, 26-2-1848, n. 35, pp. 559-561.

- Discurso sobre la provisión de prebendas, canonjías y beneficios eclesiásticos: DSC 184748, 18-3-1848, n. 49, pp. 787-790.

- Discurso sobre el proyecto de la ley de beneficencia: DSC 1848-49, 10-5-1849, n. 49, pp. 872 y $874-875$.

- Discurso sobre la disminución de los días festivos: DSC 1851-52, 27-11-1851, n. 36, pp. 412-413.

e) Correspondencia: exposiciones y cartas

- Exposiciones que ha dirigido al ministerio actual y al anterior el Excmo. Señor Obispo de Córdoba, patriarca electo de las Indias, pidiendo la vuelta a sus Iglesias de todos los Prelados que se hallan ausentes, separados de ellas, Madrid, 1844.

- Litterae Foannis Joseph Bonel et Orbe, Archiepiscopi Toletani, Hispaniarum Primatis, ad Sanctissimum Dominum Nostrum Pium Papam IX, ex commissione speciali Hispaniensis Ecclesiae Praesulum, ob exilium et tribulaciones quas impraesentiarum patitur, et Smi. Dñi. Nostri responsio, Madrid, 1849.

A este catálogo habría que añadir, en primer lugar, el resto de su correspondencia epistolar. Tenemos constancia de sus 45 cartas a la Nunciatura ${ }^{9}$. Entre 1828 y 1834 encontramos nueve misivas sobre comunicaciones oficiales. El resto, entre 1847 y 1856, versan acerca de asuntos relacionados con Roma, las relaciones Iglesia y Estado y las cuestiones de gobierno pastoral. Sería además de gran valor encontrar y adentrarse en su restante correspondencia personal.

Por último, no hemos podido hallar todavía publicados sermones pronunciados por el obispo ni tampoco algún otro tipo de escritos doctrinales.

Fondos documentales y bibliografía

Para completar el conocimiento del obispo Bonel y Orbe, una biografía crítica debería adentrarse en profundidad en los archivos que puedan contener fuentes documentales directamente relacionadas con el personaje. En primer lu-

9 Cfr. Franco DÍAZ DE CERIO, Regesto de la correspondencia de los obispos de España en el siglo XIX con los nuncios, t. 2, Ciudad del Vaticano, 1984, pp. 353-356. 
gar, desconocemos si existe algún tipo de archivo personal o familiar de Bonel y Orbe. Con respecto a los archivos diocesanos de los lugares donde gobernó, poca documentación encontramos en Málaga ${ }^{10} \mathrm{y}$ en Córdoba ${ }^{11}$. Por eso, el fondo más importante para consultar es el de Toledo ${ }^{12}$. A estos se podría añadir, por supuesto, el Archivo Secreto Vaticano -no consultado para este trabajo- y los archivos civiles de las instituciones estatales con las que se relacionó. Sin embargo, esta labor queda todavía por hacer en su mayor parte.

Con respecto a las fuentes biográficas indirectas, destacamos tres fundamentales. En primer lugar, tenemos una biografía escrita en 1852, en vida del prelado, incluida dentro de una colección de semblanzas de algunos obispos contemporáneos ${ }^{13}$. Además, contamos con dos oraciones fúnebres pronunciadas por eclesiásticos cercanos al prelado al poco de su muerte en $1857^{14}$. En estos tres documentos, especialmente en el primero, se describe de forma detallada la trayectoria personal de Juan José Bonel y Orbe. A la hora de valorar su objetividad, debemos tener en cuenta que por su género literario buscan exaltar al prelado, por lo que abundan en excesos retóricos y valoraciones subjetivas. Sin embargo, su proximidad tanto temporal como personal al obispo permiten suponer la veracidad de los datos objetivos en ellos consignados. A estas tres biografías se po-

10 El Archivo de la Curia de Málaga, con toda su documentación histórica, ardió por completo en 1931. El actual Archivo Histórico Diocesano cuenta sin embargo con fondos antiguos de parroquias y otras instituciones, donde se encuentra alguna información dispersa relativa a su pontificado (1831-1833). El Archivo de la Catedral de Málaga, mejor conservado, aporta información relevante, especialmente acerca de la vida del cabildo al que perteneció Bonel y Orbe entre 1816 y 1831 (p. ej., el legajo 49 contiene su prueba de limpieza de sangre), y los gobiernos en sede vacante.

11 A pesar de que este fue su pontificado más extenso (1833-1847), no existe mucha documentación en el Archivo diocesano de Córdoba. Esto se debe al absentismo de Bonel y Orbe en esta diócesis y a la norma general que existía de que los obispos se llevaran su documentación al salir de Córdoba. Encontramos, no obstante, algunos documentos en la sección «Órganos de gobierno/pastoral»: signatura 10115; «Expolios»: sign. 9666/05; y «Despachos ordinarios»: sign. 7410/020, 7387/067, 7347/122, 7322/059, 7160/022, 7033/130, 7043/031, 7049/040. Esta ausencia la corrobora también Pedro Pablo Herrera MESA, Escritos pastorales de los obispos de Córdoba (16271857), Córdoba, 2004, pp. 108-111.

12 En el Archivo diocesano de Toledo, dentro del «Fondo Pontificados», se encuentran 28 cajas sin clasificar relativas al pontificado de Bonel y Orbe (1847-1857).

13 Vicente María BRUSOla y Niceto HERnáNDEZ DE FUENTES, Biografías de los obispos contemporáneos, prelados y demás dignidades ilustres de la Iglesia Española redactadas a vista de notas, apuntes y documentos auténticos, Madrid, 1852, pp. 35-44.

14 Esteban José PÉREZ, Oración fúnebre que a la inmortal memoria del Emmo. Señor Don fuan fosé Bonel y Orbe, Madrid, 1857; José Pedro DE AlcánTara RodrígueZ, Oración fúnebre del Emmo. Señor Don Juan Fosé Bonel y Orbe, Madrid, 1858. 
dría añadir otra contenida en un libro escrito a mediados del siglo XIX, Personajes ilustres, y transcrita en la página web del ayuntamiento granadino de Dúrcal ${ }^{15}$. Además, existen algunas otras fuentes secundarias que nos permiten profundizar en aspectos parciales de la vida de Bonel y Orbe, como su formación intelectual ${ }^{16}$, su labor parlamentaria ${ }^{17}$ o su ministerio pastoral ${ }^{18}$.

En cuanto a la bibliografía más actual, se ha descubierto una notable ausencia de estudios historiográficos. Como de otros muchos prelados de esta centuria, la única información reciente está contenida en esquemáticas biografías de voces de diccionarios y breves artículos ${ }^{19}$. En ellos se contienen repetidamente las mismas noticias de la vida de Bonel y Orbe, casi siempre sin ningún tipo de valoración más allá de categorías generales. Además, se hallan algunas informaciones secundarias y concretas en obras de historia generales.

Por todo lo expuesto, podemos decir que esta aproximación que vamos a realizar se puede considerar la biografía más completa hecha hasta ahora del cardenal Juan José Bonel y Orbe. Sin embargo, no pretendemos otra cosa que una recopilación del material publicado existente y disperso por la bibliografía, con el objetivo de mostrar la relevancia histórica de un personaje hasta ahora, en gran medida, desconocido.

15 http://www.adurcal.com/enlaces/mancomunidad/titulos/bonel/jjbonelorbe.htm (última consulta: 21-05-2018).

16 Relación de los méritos, grados y exercicios literarios del doctor don fuan fosé Bonel y Orbe. Examinador Sinodal de Granada y Guadix, 1814; Francisco MARTÍNEZ LuMBrERAS, Una fundación granadina. Historia del Real Colegio de S. Bartolomé y Santiago, Granada, 1915, p. 166.

17 Estadística de personal y vicisitudes de las Cortes y de los Ministerios de España. Desde el 29 de septiembre de 1833, en que falleció el Rey D. Fernando VII, hasta el 11 de septiembre de 1858, en que se disolvió el Congreso de los Diputados, Madrid, 1858; Diarios de las sesiones de Cortes, tanto del Estamento de Próceres como del Senado.

18 Antonio R. DE VARGAS, Instrucción sobre los Seminarios eclesiásticos llamados conciliares, y con especialidad sobre el de S. Sebastián de la ciudad de Málaga, Montevideo, 1844, pp. 205-209.

19 Cfr. Aniceto OrIVE, Bonel y Orbe, Fuan fosé, en Quintín AldEA, Tomás MARÍn y José Vives, Diccionario de Historia Eclesiástica de España, t. 1, Madrid, 1972, p. 273; Francisco MONDÉJAR CUMPIÁN, Obispos de la Iglesia de Málaga, Córdoba, 1998, pp. 331-334; Francisco OdrIOZOLA ARGOS, Juan Fosé Bonel y Orbe. Un obispo preconizado para la diócesis de Santander, en Altamira, 69 (2006), pp. 107-118, esp. 108-109; Vicente CÁRCEL ORTí, Bonel y Orbe, Juan Fosé, en Gonzalo ANES Y Álvarez de Castrillón (dir.), Diccionario Biográfico Español, t. 8, Madrid, 2010, pp. 719-721; Diego Caro Cancela y Fernando MarTínez LóPez, Bonel y Orbe, Zuan Fosé, en Diego Caro CanCEla (dir.), Diccionario biográfico de parlamentarios de Andalucía, 1810-1869, Sevilla, 2010, pp. 249-250; Alberto GIL Novales, Bonel y Orbe, Zuan Fosé, en Diccionario biográfico de España (1808-1833), t. 1, Madrid, 2010, p. 444. 


\section{ITINERARIO BIOGRÁFICO DEL CARDENAL BONEL Y ORBE}

\section{Formación y trayectoria de un eclesiástico del Antiguo Régimen}

Juan José Bonel y Orbe nació el 17 de marzo de 1782 en Pinos de Rey, una pequeña población cerca de Granada. Era descendiente de una familia de linaje, hijo primogénito de Nicolás Bonel y Martín, y Ana María de Orbe y Orbe; y hermano de Nicolás, I marqués de Márgena. Contó además con varios parientes eclesiásticos. Con once años de edad fue ya destinado a la carrera literaria y enviado para estudiar latín y ciencias en el colegio granadino de san Jerónimo, dando muestras de una despierta inteligencia. Más tarde, se ciñó el 5 de octubre de 1796 la beca de colegial jurista en el real Colegio de san Bartolomé y Santiago en Granada $^{20}$. Allí cursó los estudios de filosofía, historia, derecho civil y canónico y teología, obteniendo el doble título de Doctor en Derecho Civil y en Cánones ${ }^{21}$ el 4 de mayo de 1804, apenas cumplidos los 22 años. Fue ordenado sacerdote en $1805^{22}$ en Alcalá la Real (Jaén), por el obispo abad fray Manuel María Trujillo (1728-1814). Desde entonces continuó su carrera académica en el claustro de profesores de la Universidad de Granada, en la cátedra de Historia de los Concilios generales y de sagrados Cánones, así como en muchos otros cargos.

Desgraciadamente, la documentación biográfica no profundiza en la formación intelectual que recibió ${ }^{23}$, por lo que es necesario acudir a estudios generales ${ }^{24}$.

20 Acerca de este Colegio, fundado en 1649 por el jesuita Pedro de Fonseca, existen numerosos estudios, todos ellos recogidos en el más moderno: María José OsORIO PÉREZ, Historia del Real Colegio de San Bartolomé y Santiago, Granada, 1987. Este se centra fundamentalmente en aspectos jurídicos, organizativos y económicos.

21 Sólo el 10\% de los obispos españoles entre 1789 y 1845 fueron doctores a la vez en Derecho civil y canónico. Cfr. José Manuel CUENCA TORIBIO, Sociología del episcopado español e hispanoamericano (1789-1985), Madrid, 1986, p. 143.

22 Cfr. Remigius RITZLER y Pirminus SEFRIN, Hierarchia Catholica medii et recentiores aevi, t. 7, Patavii, 1968, p. 250.

23 Conocemos algunas de las materias y libros básicos que se emplearon. Cfr. Francisco MARTínEZ LUMBRERAS, Una fundación... [ver n. 16], p. 166, donde se menciona a Bonel y Orbe como miembro de «uno de los núcleos más brillantes de alumnos conocidos en el Colegio». En la n. 2 se transcribe su hoja de estudios en Cánones y se reconocen sus extraordinarias dotes intelectuales (obtuvo en todas las materias la nota de excedit primo loco cum nota speciali), su piedad y el cumplimiento de sus deberes tanto literarios como políticos. Recibió el título de canonista el 18-5-1803.

24 Cfr. Francisco MARTÍN HERNÁNDEZ, La formación del clero en los siglos XVII y XVIII, en Ricardo GARCÍA-VILlOSLADA y Antonio MESTRE SANCHÍs (dirs.), Historia de la Iglesia en España, t. 4, Madrid, 1979, pp. 556-582; Alfredo MARTíneZ AlbiaCH, Fe y razón entre dos concordatos (1753-1851), en Melquíades ANDRÉS MARTínEZ (dir.), Historia de la teología española, t. 2, Madrid, 1987, pp. 443-481. 
El siglo XVIII español fue un «siglo nada teológico, las cuestiones canónicas se sobrepusieron a todo» ${ }^{25}$, continuando así la decadencia de la teología universitaria. Con respecto a la formación canónica, sobresalió una actitud jansenista, no centrada tanto en cuestiones doctrinales o teológicas (como el jansenismo europeo) cuanto en su vertiente canónica y política. La esencia de este «jansenismo español» se encontraría en el campo jurisdiccional: austeridad y celo por la antigua disciplina, episcopalismo y conciliarismo, antirromanismo y furibundo regalismo... ${ }^{26}$ Todo este movimiento vino alentado por los gobiernos del despotismo ilustrado, para llevar adelante sus planes regalistas mediante el control de la enseñanza.

Cuando Bonel y Orbe ingresa en el Colegio de San Bartolomé y Santiago en 1796, ya se habían promulgado los decretos que anulaban la independencia de los colegios universitarios y disponían la uniformización de los estudios según el ideario ilustrado ${ }^{27}$. La Universidad de Granada, más incluso que otras universidades españolas, conoció un plan con una «tendencia bastante innovadora, (...) abierto a las nuevas corrientes teológicas y a un cierto espíritu "jansenista"», con unos estudios eclécticos, caracterizados por el rechazo del escolasticismo y la «implantación de los regalistas y jansenistas más conocidos de Europa» ${ }^{28}$. Por tanto, cabe suponer que Bonel recibió allí una formación canónica y teológica especialmente marcada por el regalismo, el episcopalismo y la sospecha hacia la potestad romana.

El ascenso por la carrera eclesiástica de Bonel y Orbe es un claro ejemplo del cursus honorum que ascendía al episcopado por los diversos escalafones. El arzobispo de Granada, Juan Manuel de Moscoso y Peralta (1723-1811), reconoció las dotes del joven canonista y el 31 de agosto de 1805, recién ordenado sacerdote, le nombró familiar suyo, secretario y consultor; y más tarde fiscal ge-

25 Marcelino MEnÉndeZ Pelayo, Historia de los heterodoxos españoles, t. 2, Madrid, 2011, p. 276.

26 Cfr. Antonio MeSTRE SANCHÍs, El jansenismo español de los siglos XVII y XVIII, en Augustin FLICHE y Victor MARTIN (dirs.), Historia de la Iglesia, t. 22, Valencia, 1976, pp. 563-585; Gérard DufOuR, De la Ilustración al Liberalismo. El clero jansenista, en Armando AlbEROLA Romá y Joseph PÉREZ (coords.), España y América entre la Ilustración y el liberalismo, Alicante-Madrid, 1993, pp. 5768. Dufour insiste en que este jansenismo, conforme van surgiendo nuevos estudios, aparece como más difundido entre el clero español.

27 Cfr. María José Osorio PéreZ, Historia ... [ver n. 20], pp. 118-136.

28 Inmaculada ARIAS DE SAAVEDRA, Las reformas ilustradas. Siglo XVIII, en María del Carmen CALERO, Inmaculada ARIAS y Cristina VIÑET, Historia de la Universidad de Granada, Granada, 1997, pp. 128-133. Aquí se estudian las reformas en Teología y Derecho del nuevo plan de estudios de 1776. 
neral del arzobispado durante siete años ${ }^{29}$. Hasta la muerte del prelado el joven clérigo le ayudó en el despacho de asuntos eclesiásticos. Sin cumplir aún la edad canónica, fue presentado para el curato parroquial de san Pedro y san Pablo de la capital granadina, del que tomó posesión el 17 de marzo de 1806. Allí se ganó la confianza del clero, siendo elegido en 1808 presidente del cabildo de curas, cargo en el que continuó mientras fue párroco. A este le sucedieron numerosos nombramientos diocesanos. Ciertamente, nos encontramos ante una personalidad considerada y reconocida en el ambiente eclesiástico granadino.

Durante la invasión napoleónica y posterior guerra de la Independencia, el arzobispo de Granada se retiró a las Alpujarras. Su consejero Bonel y Orbe «le acompaña, le precede en su vuelta, y se constituye intérprete entre su señor y los generales franceses» ${ }^{30}$. Con toda probabilidad, en aquella época fue un afrancesado convencido ${ }^{31}$.

En 1815 Bonel y Orbe hizo una oposición a la canonjía doctoral de la catedral de Granada, quedando en segundo lugar. Más tarde se presentó a idéntico puesto en Málaga, y propuesto unánimemente por el cabildo, tomó posesión como canónigo doctoral ${ }^{32}$ el 10 de agosto de 1816, continuando durante catorce años. Bonel y Orbe continuó ocupando cargos de alta responsabilidad en Málaga, pues el obispo, Alonso Cañedo y Vigil (1760-1829), le nombró provisor y vicario general y, más tarde, gobernador eclesiástico. De este modo, se situó al frente de la curia como el principal auxiliar y consejero del obispo, y el segundo personaje más importante de la diócesis.

El gobernador eclesiástico, hombre de confianza del obispo Cañedo, tuvo que enfrentarse a los difíciles conflictos políticos y religiosos del Trienio liberal $(1820-1823)^{33}$. La ciudad de Málaga, presa de un furibundo anticlericalismo, vio

29 El fiscal general, uno de los cargos diocesanos más importantes, se encargaba de «vigilar los comportamientos religiosos y los derechos de la Iglesia», $\mathrm{y}$ «de que los delitos públicos no queden sin castigo» (Maximiliano BARRIO GOZALO, El clero en la España moderna, Córdoba, 2010, p. 209).

30 Cfr. Esteban José PÉREZ, Oración... [ver n. 14], p. 14.

31 Cfr. Alberto GIL Novales, Bonel... [ver n. 19], p. 444. Allí cita La Gazeta de Madrid, no 90 (31-31810), pp. 379-380, que recoge una arenga pronunciado por Bonel y Orbe ante José Bonaparte el 19-3-1810, ofreciéndole «el testimonio de obediencia, de fidelidad y vasallaje que le habemos jurado».

32 El oficio de canónigo doctoral consistía «en asesorar al cabildo en las cuestiones jurídicas y defenderlo en los pleitos» (Maximiliano BARRIO GOZALO, El clero... [ver n. 29], p. 209).

33 Cfr. Manuel RevUelta GONZÁLEZ, Política religiosa de los liberales en el siglo XIX, Madrid, 1973; José GoÑi GaZTambide, El obispo de Málaga, Cañedo, en el Trienio Constitucional, en Hispania Sacra, 32 (1980), pp. 193-227; Maximiliano BARRIO GOZALO, La Santa Sede y los obispos españoles en el Trienio liberal (1820-1823), Roma, 2015, pp. 51 y 216. 
en octubre de 1822 cómo su prelado era condenado a exiliarse a Gibraltar. El cabildo, en una revuelta elección bajo fuerte presión popular y gubernamental, escogió como gobernador eclesiástico a Pedro Muñoz Arroyo, querido por el gobierno, en vez del designado por el obispo y entonces gobernador, Bonel y Orbe. En medio de esta revolución y por ausencia del obispo, Bonel y Orbe desempeñó una labor de gran responsabilidad en los negocios eclesiásticos y en las juntas populares a las que asistió por oficio ${ }^{34}$. Ya entonces comenzaron sus tratos con los reformadores liberales. También recibió reconocimientos de la sociedad civil, formando parte de una Junta de Sanidad y de una Sociedad de amigos del país.

De cara a profundizar en su trayectoria biográfica, sería muy interesante ahondar en estos acercamientos de Bonel a los incipientes elementos liberales en los primeros decenios del siglo XIX: afrancesados, reformadores de Cádiz, constitucionalistas del Trienio... Todo ello podría arrojar mucha luz sobre las posturas que más adelante tomará. Sin embargo, no poseemos más información biográfica.

Obispo de Málaga (1831) y de Córdoba (1833) durante las regencias isabelinas

En 1827, tras fallecer el obispo fr. Manuel Martínez (1774-1827), el cabildo de Málaga nombró a Bonel y Orbe vicario capitular sede vacante con jurisdicción plena. Al tomar posesión el nuevo prelado, Juan Gómez Durán (1767-1830), le mantuvo en su triple carácter de gobernador, provisor y vicario general. Finalmente, Fernando VII, el 15 de febrero de 1829, eligió a Bonel y Orbe como obispo de Santander ${ }^{35}$. Sin embargo, fue promovido el 16 de mayo de 1830 a la dignidad de arcediano de Antequera. Poco tiempo después, el 26 de junio, fue electo obispo de Ibiza. Tras recibir la cédula de confirmación real, el recién elegido pasó a Granada y a su pueblo natal para despedirse antes de partir a la isla.

Pero la sede de Málaga volvió a quedar vacante por el fallecimiento de Gómez Durán. El cabildo llamó entonces otra vez a Bonel y Orbe y le nombró de nuevo gobernador, deseando que él fuera el próximo prelado de la ciudad. Finalmente, el 27 de julio de 1830 fue presentado por el rey como obispo de Málaga,

34 Cfr. Esteban José PÉREZ, Oración... [ver n. 14], pp. 17-18; Vicente María Brusola, Niceto HerNÁNDEZ DE FUENTES, Biografías... [ver n. 13], p. 39.

35 De tan efímero nombramiento sólo tenemos constancia por Francisco ODRIOZOLA ARGOS, fuan Fosé... [ver n. 16], p. 107. Fue nombrado con 46 años, diez años más joven que la media de preconización de los obispos españoles, cfr. José Manuel CuENCA TORIBIO, Sociología... [ver n. 21], p. 17. 
siendo preconizado el 28 de febrero de 1831 por el papa Gregorio XVI, culminando así su fulgurante trayectoria ${ }^{36}$. Después de dos nombramientos fallidos, por fin tomó posesión por poderes el 16 de mayo. Fue consagrado obispo el 12 de junio en la iglesia metropolitana de Granada por el arzobispo Blas Joaquín Álvarez de Palma (1754-1837). Después de un viaje por su tierra natal y por Madrid, se dirigió a Málaga en octubre.

Sin embargo, en esta sede duró sólo dos años. El obispo tuvo que ser trasladado por el ambiente enrarecido que se había creado en la ciudad, a causa del levantamiento del general liberal Torrijos en $1831 \mathrm{y}$ su posterior fusilamiento por orden del Rey ${ }^{37}$. El 15 de febrero de 1833 el obispo Bonel y Orbe fue elegido por Fernando VII para la mitra de Córdoba, por el fallecimiento de Pedro Antonio Trevilla (1755-1832). Fue promovido a esa sede por el papa Gregorio XVI el 29 de julio ${ }^{38}$. Sin embargo, permaneció en Málaga, pues se declaró durante el verano una nueva plaga del cólera y el prelado no quiso abandonar a sus feligreses. Por fin, el 20 de enero de 1834 tomó por poderes posesión del obispado de Córdoba, para donde salió el 7 de marzo.

En medio de las difíciles circunstancias históricas de las regencias isabelinas (1833-1843), el recién nombrado obispo de Córdoba fue designado para ocupar uno de los asientos del Estamento de Próceres apenas creado ${ }^{39}$. Así, tuvo que trasladarse en julio de 1834 a Madrid, dejando la ciudad de Córdoba a los cuatro meses de su llegada. Desde entonces mantuvo, casi sin interrupción, su escaño parlamentario en la Cámara alta. Primero, con el Estatuto Real de 1834, como prócer del reino. Más tarde, con la Constitución progresista de 1837 fue nombrado, en la primera legislatura, senador electivo por la provincia de Almería el 15 de diciembre de $1837^{40}$. El 22 de mayo de 1840 fue reelegido por la provincia

36 Cfr. Remigius Ritzler y Pirminus Sefrin, Hierarchia, t. 7... [ver n. 22], p. 250. El caso de Bonel y Orbe es un claro ejemplo del nomadismo episcopal, muestra de la absoluta supremacía del Estado en este tipo de nombramientos, que realizaba según sus intereses y necesidades; cfr. José María CuenCa Toribio, Sociedad y clero en la España del siglo XIX, Córdoba, 1980, pp. 381-397.

37 Cfr. Francisco Mondéjar Cumpián, Obispos... [ver n. 19], p. 333. Aunque Bonel y Orbe fue uno de los que pidieron clemencia a Fernando VII, al virar la política nacional hacia una mayor apertura, el prelado fue acusado de connivencia con el absolutismo por permitir tal represión.

38 Cfr. Remigius Ritzler y Pirminus SEFrIN, Hierarchia, t. 7 ... [ver n. 22], p. 163.

39 Cfr. Estadística de personal... [ver n. 17], pp. 33 y 563. Acerca del Estamento de Próceres y del Senado, cfr. Luis SÁNCHEZ AGESTA, Historia del constitucionalismo español, Madrid, 1984; Emma Montanos Ferrín y José SÁNCHEZ-ArCiLla Bernal, Historia del derecho y de las instituciones, t. 3, Madrid, 1991.

40 Cfr. Estadística de personal... [ver n. 17], p. 171. 
de Granada ${ }^{41}$ y permaneció en su escaño hasta la segunda legislatura de 1843. Por último, con la Constitución moderada de 1845, fue nombrado por la Corona el 15 de agosto de 1845 senador vitalicio, jurando su cargo al comienzo de la primera legislatura $^{42}$. En este oficio político permaneció hasta 1853 , cuando se interrumpió la actividad parlamentaria. De ese modo, desde 1834 hasta su muerte ocupó un asiento parlamentario en todas las legislaturas salvo tres: 1839, 18431844 y $1844-1845$.

La carrera política de Bonel y Orbe estuvo muy vinculada no sólo a las instituciones parlamentarias, sino también a la misma corte de Isabel II. Fue nombrado el 19 de julio de 1839 patriarca de las Indias Occidentales ${ }^{43}$, cargo honorífico que mantuvo hasta 1847 y que llevaba asociado el de capellán mayor y vicario general de los ejércitos ${ }^{44}$. Además, la Reina (de apenas 7 años) y la infanta Luisa Fernanda le eligieron como su confesor en octubre de 1840. En este puesto tan influyente permaneció hasta su muerte en 1857, siendo entonces sustituido por Antonio María Claret ${ }^{45}$. Su servicio en pro de la causa isabelina le fue recompensado también con muchas distinciones: canciller mayor, capellán mayor de San Isidro, caballero de las Órdenes de Carlos III y de Isabel la Católica, comisario general de Cruzada... Por último, el 18 de octubre de 1838, Bonel y Orbe fue presentado para el arzobispado de Granada. Sin embargo, a causa de la paralización de los nombramientos episcopales, el obispo de Córdoba no fue confirmado canónicamente ni reconocido por el cabildo.

\section{Arzobispo de Toledo (1847) y cardenal (1850) durante el periodo moderado}

Una vez proclamada la mayoría de edad de la Reina adolescente, gobernando ya los liberales moderados y restablecidas las relaciones con la Santa Sede, se

41 Cfr. Colección de las leyes, decretos y declaraciones de las Cortes XXVI, Madrid, 1841, pp. 179-180.

42 Cfr. Estadística de personal... [ver n. 17], p. 348.

43 Cfr. Vicente CÁRCEL ORTí, Política eclesial de los gobiernos liberales españoles (1830-1840), Pamplona, 1975, pp. 228-231. Este nombramiento sucedió mientras todavía vivía el legítimo patriarca, Antonio Allué. Bonel y Orbe, por tanto, aceptó el cargo sin la autorización del Papa. A la muerte de Allué en 1842, Bonel y Orbe fue autorizado en este cargo por la Santa Sede durante un quinquenio.

44 Estos tres cargos fueron unidos en 1762 por un breve de Clemente XIII, cfr. Félix RUIZ GARCÍA, Patriarcado de Indias y Vicariato General Castrense, en Revista Española de Derecho Canónico, 23 (1967), pp. 449-471.

45 Así lo atestigua el propio Claret en carta a Pío IX, cfr. Antonio María ClarET, Cartas selectas, Madrid, 1996, pp. 265-266. Igualmente, en su autobiografía, cfr. Antonio María ClARET, Escritos autobiográficos, Madrid, 1981, p. 320. 
procuró resolver el problema urgente de las sedes vacantes, entre las que se encontraba la primada. El 6 de abril de 1845 el Papa Gregorio XVI nombró a Bonel y Orbe administrador apostólico de Almería. Pero el prelado fue presentado por Isabel II el 12 de septiembre de 1847 para el arzobispado de Toledo, demostrando así la confianza y estima de la corte y la soberana. Fue preconizado por Pío IX a esa sede el 4 octubre $^{46}$ y, al ser designado primado de las Españas, se convirtió en el obispo más influyente de la nación. El 1 de enero de 1848 Bonel y Orbe recibió el palio arzobispal de manos del nuncio en Madrid y el 23 el deán tomó posesión de la diócesis toledana en su nombre, por causa de una enfermedad. Una vez restablecido, verificó su entrada pública el 21 de enero de 1849, en medio de aclamaciones de toda la población.

Después de una larga carrera, el papa Pío IX le promovió al cardenalato el 30 de septiembre de $1850^{47}$, recibiendo el birrete de manos de Isabel II. El cardenal Bonel y Orbe falleció en Madrid el 11 de febrero de 1857, siendo llorado por la misma Reina y toda la corte. Sus restos mortales reposan en la capilla de Santiago de la Catedral toledana.

\section{LA DOBLE FACETA DE UN OBISPO ESPAÑOL DEL SIGLO XIX}

Se ha consagrado ya en el ámbito historiográfico hablar de las diversas facetas que una figura histórica puede desarrollar en su actuación en el mundo. Así se ha visto en el caso de la monarquía o el papado ${ }^{48}$. También podemos hablar del carácter multiforme del ministerio episcopal, tal y como se ha configurado a lo largo de los siglos según una enorme variedad de aspectos: pastor, doctor y maestro, padre de los pobres, señor feudal, político y estadista, capitán militar...

En el itinerario biográfico de Bonel y Orbe sobresalen dos facetas fundamentales: su papel de pastor de la Iglesia y su perfil de político y parlamentario. Ambas no pueden verse como contrapuestas entre sí; al contrario, este caso demuestra que son mutuamente complementarias. La trayectoria política del prelado granadino manifiesta hasta qué punto el obispo concebía este modo de participación pública como una manera concreta y decisiva de ejercer su ministerio

46 Cfr. Remigius RITZler y Pirminus SEFrIn, Hierarchia Catholica medii et recentiores aevi, t. 8, Patavii, 1978, p. 558.

47 Cfr. Remigius Ritzler y Pirminus Sefrin, Hierarchia, t. 8... [ver n. 46], p. 10.

48 Por ejemplo, Ernst H. Kantorowicz, Los dos cuerpos del rey, Madrid, 1985; Paolo ProDi, El soberano pontifice. Un cuerpo en dos almas, Madrid, 2010. 
pastoral. Esto no nos puede resultar extraño si pensamos que el diálogo con el Estado resulta esencial en la tarea de defender los derechos de la Iglesia, considerados indispensables para que esta realice adecuadamente su misión evangelizadora. A continuación, nos adentraremos, a la luz de la biografía de Bonel y Orbe, en la doble faceta de un obispo español de mediados del siglo XIX.

\section{Bonel y Orbe, pastor de la Iglesia}

De entre todas las cualidades de la personalidad de Juan José Bonel y Orbe hay tres que sobresalen en las fuentes biográficas conservadas ${ }^{49}$. En primer lugar, fueron muy alabadas sus capacidades intelectuales, demostradas en sus estudios, en el rápido ascenso por los grados académicos y en la docencia. El reconocimiento de sus dotes intelectuales y su amplia formación teológica y canónica le acompañará toda su vida. En segundo lugar, destacó su fulgurante carrera por los diversos cargos eclesiásticos que desempeñó. Los prelados de Granada y Málaga se apoyaron en él para regir sus diócesis y se fiaron de su mediación en periodos difíciles. También tuvo la confianza de los cabildos y los sacerdotes de ambas diócesis. En sus respectivos destinos pastorales fue ensalzada su capacidad de gobierno, dedicación y caridad solícita en el ministerio. Por último, destaca también su capacidad de influencia en diversos ambientes eclesiásticos y civiles, donde fue un clérigo reconocido. Como ha quedado patente en el itinerario biográfico, este prelado tuvo necesidad de moverse en entornos políticos muy diversos, dialogando con franceses, liberales del Trienio, absolutistas fernandinos, liberales progresistas y moderados... siempre en defensa de los intereses de la Iglesia.

Por paradójico que sea, contamos con más información sobre el gobierno de Bonel y Orbe en la diócesis de Málaga, de duración mucho más breve, que en la de Córdoba. Las fuentes destacan de su oficio episcopal en Málaga el ministerio de la predicación, que ejercía con frecuencia en la catedral; las cartas pastorales que escribió; las habituales visitas a las parroquias, hasta las aldeas más remotas; su caridad con los pobres, necesitados y enfermos, incluso fundando un hospital para niños tiñosos; la construcción de nuevas iglesias; y su cuidado por el decoro

49 Contamos especialmente con las valoraciones que realizan Vicente María BRUSOLA y Niceto HERNÁNDEZ DE FUENTES, Biografías... [ver n. 13], pp. 35-44; Esteban José PÉREZ, Oración... [ver n. 14]; José Pedro DE AlCÁnTARa Rodríguez, Oración... [ver n. 14]. Como ya hemos indicado, a pesar de su carácter laudatorio (propio de su género literario), estas fuentes reflejan aspectos reales de la personalidad de Bonel y Orbe contrastados con su itinerario biográfico. 
del culto divino. También dedicó muchos esfuerzos a mejorar el seminario y al aumento del número de pastores ${ }^{50}$. En esos dos años demostró tal celo pastoral que «en una palabra, el Ilmo. Sr. Bonel y Orbe al tomar posesión de la Mitra de Málaga tenía la ciencia de gobernar» ${ }^{51}$. La clave del éxito del ministerio de Bonel y Orbe en esta ciudad fue su capacidad de relación e influencia y su conocimiento de las personas encargadas de los diversos oficios eclesiásticos, unido a su experiencia personal.

No se puede decir lo mismo, sin embargo, de su largo gobierno de la diócesis de Córdoba: «brilló por su ausencia en circunstancias muy difíciles para la diócesis (exclaustración y desamortización), rigió el obispado mediante gobernador eclesiástico $\gg^{52}$. Las responsabilidades políticas y cortesanas le obligaron a prolongadas ausencias de su sede, lo cual dificultaba grandemente la labor pastoral. A pesar de su incumplimiento del deber de residencia, no faltan algunas valoraciones positivas: «en el transcurso de las legislaturas regresó varias veces a su diócesis, aprovechando las suspensiones de los trabajos legislativos, para continuar la visita de ella y ocuparse de las funciones pastorales» ${ }^{53}$. Además, el obispo permaneciendo en Madrid sustituyó frecuentemente a González Vallejo, enfermo e impedido, en su labor episcopal en Toledo ${ }^{54}$. En cuanto a la atención al clero, pese a su absentismo supo mantener «una relación afectiva con el cabildo y sus problemas ${ }^{55}$. Sin embargo, sus prolongadas ausencias le obligaron a nombrar un gobernador eclesiástico, Joaquín $\mathrm{M}^{\mathrm{a}}$ Villavicencio, dócil a los planes reformistas liberales. Como consecuencia, un sector del clero cordobés se mostró reacio a su pastor tanto por sus inclinaciones políticas como por su absentismo. En su carta de despedida, el mismo Bonel y Orbe «admitía -a destiempo- sus largas y frecuentes ausencias, llegando a reconocer sus nocivos efectos» ${ }^{56}$.

50 Cfr. Antonio R. DE VARGAS, Instrucción... [ver n. 18], pp. 205-209; Francisco MONDÉJAR CUMPIÁN, Obispos... [ver n. 19], p. 333; Esteban José PÉREZ, Oración... [ver n. 14], pp. 21-23; José Pedro DE AlCánTara RodrígueZ, Oración... [ver n. 14], pp. 19-26. Aquí tenemos más bien la descripción de lo que se entendía a mediados del siglo XIX como un buen obispo.

51 Antonio R. DE VARGAS, Instrucción... [ver n. 18], pp. 206.

52 Manuel Nieto CumPlido (coord.), Historia de las diócesis españolas, t. 8. Iglesias de Córdoba y faén, Madrid-Córdoba, 2003, pp. 155 y 186. Según Pedro Pablo Herrera MESA, Escritos... [ver n. 11], pp. 108-111, durante su pontificado cordobés sólo escribió personalmente una carta pastoral, en 1847 con motivo de su despedida.

53 Vicente CÁRCEL ORTí, Bonel... [ver n. 19], p. 719.

54 Cfr. Vicente CÁRCEl OrTí, Política... [ver n. 43], p. 465.

55 José GARCÍA-CUEVAS VENTURA, El cabildo catedralicio cordobés desde la revolución a la Restauración (1788-1882), Córdoba, 1996, p. 171.

56 José García-Cuevas Ventura, El cabildo... [ver n. 55], p. 173. 
Una vez elegido arzobispo de Toledo, pudo ya residir sin problemas en Madrid $^{57}$, intensificando sus contactos en la corte. Además, mantuvo relaciones con muchos eclesiásticos influyentes ${ }^{58}$. En 1849 tuvo una disputa pública con el arzobispo de Tarragona, Echanove y Zaldívar (1765-1854) acerca de la primacía de Toledo sobre la diócesis tarraconense $\mathrm{e}^{59}$. De su pontificado toledano las fuentes destacan las cartas pastorales que dirigió a sus fieles en diversas ocasiones. La mitad de las que tenemos noticia versan sobre temas romanos: las rogativas públicas por el Papa, la proclamación del dogma de la Inmaculada y los jubileos de 1850 y 1854. El resto atañen a cuestiones pastorales de la diócesis, como el establecimiento de la obra de la Santa Infancia, el socorro de los necesitados de Galicia y la abstención de ciertas diversiones. Un estudio detallado de toda su producción pastoral es necesario para calibrar el verdadero alcance e importancia de Bonel y Orbe.

Además, el arzobispo comenzó a dar numerosas muestras de cercanía, afecto y devoción al papa Pío IX, estrechando sus lazos con la Santa Sede. Con motivo de la penosa huida del pontífice a Gaeta a causa de la revolución liberal romana de 1848, el primado escribió una carta pastoral pidiendo rogativas por él. También le dirigió a Pío IX en persona una sentida epístola en nombre de todo el episcopado español el 8 de marzo de 1849, a la cual respondió el Papa el 17 de abril. Además, lanzó a instancias del nuncio una campaña entre los obispos españoles para recaudar un donativo en socorro del obispo de Roma ${ }^{60}$. Por último, retomó e intensificó su correspondencia epistolar con la nunciatura de Madrid, interrumpida desde $1834^{61}$. Estas demostraciones de pública adhesión al Papa y las recomendaciones hechas por Isabel II, ciertamente movieron a Pío IX a proclamarle cardenal en 1850, culminando así su carrera eclesiástica. Además, en el año 1854, a pesar de hallarse ya con las fuerzas debilitadas, pudo asistir a la declaración del dogma de la Inmaculada Concepción en Roma y recibir de Pío IX el capelo cardenalicio, el nombramiento para varias congregaciones y otra multitud de pruebas del mayor aprecio.

57 Residía habitualmente en el palacio de la calle san Justo en Madrid y el de san Pascual en Aranjuez, cfr. Vicente María BruSOla y Niceto HeRnáNDEZ dE FuENTES, Biografías... [ver n. 13], p. 43. La procedencia de sus cartas en este periodo así lo confirma, cfr. Franco DíAz DE CERIO, Regesto, t. 2... [ver n. 9], pp. 354-356.

58 Por ejemplo, con el entonces canónigo toledano Monescillo, cfr. Rafael María SANZ DE DIEGO, Medio siglo... [ver n. 1], p. 20. También con Claret, cf. Antonio María ClaRET, Cartas... [ver n. 45], p. 58.

59 Cfr. Franco DÍAZ DE CERIO, Regesto de la correspondencia de los obispos de España en el siglo XIX, t. 3, Ciudad del Vaticano, 1984, p. 429.

60 Cfr. Vicente CáRCEL ORTí, El liberalismo... [ver n. 4], pp. 193-194. Bonel y Orbe contribuyó personalmente con 35.000 reales a este donativo que alcanzó los 600.000.

61 Cfr. Franco DÍAZ DE CERIO, Regesto, t. 2... [ver n. 9], pp. 354-356. 
Bonel y Orbe, político y parlamentario: ¿un obispo liberal moderado?

En virtud del concordato de 1753, todos los cargos episcopales eran presentados por el Rey de España al Papa. Por ese motivo, la política real fue un elemento decisorio en los nombramientos episcopales. Así, si bien las designaciones hechas durante los primeros años de la década ominosa recayeron sobre personajes opuestos a toda reforma, las últimas presentaciones episcopales de Fernando VII antes de su muerte designaron a candidatos más afines a los nuevos ideales liberales. Entre estos nuevos obispos liberales nombrados a comienzos de la década de 1830, encontramos ciertamente a Bonel y Orbe, junto a Torres Amat (obispo de Astorga, 1772-1847), Martínez de San Martín (Barcelona, 1773?-1849) o Ramo de San Blas (Huesca, 1771-1845). Todos ellos «habían estado comprometidos, de algún modo y a niveles distintos, con los revolucionarios del Trienio. Estos mismos obispos colaboraron de forma más o menos explícita con el nuevo régimen, y, desde luego, simpatizaron abiertamente con la ideología liberal menos radicalizada $»^{62}$. Es posible observar, por tanto, una línea de continuidad reformista desde los prelados ilustrados del siglo XVIII, imbuidos de espíritu regalista y episcopalista, pasando por los clérigos de las cortes de Cádiz ${ }^{63}$ y los obispos liberales del Trienio ${ }^{64}$, hasta este intento de crear un nuevo episcopado afín al ideario liberal durante la época de las regencias. En todos los casos se trata de un afán del gobierno por crear una Iglesia amoldada a sus proyectos políticos e ideológicos.

Todo ello generó una división profunda entre el episcopado español durante la década 1833-1843, coincidiendo con la primera guerra civil carlista. Los prelados llamados «liberales», once en total, fueron ascendidos con los reconocimientos del gobierno, y no se vieron molestados en su jurisdicción. Sin embargo, otros 18 obispos fueron perseguidos por el gobierno y desterrados. Otros siete obispos, a pesar de permanecer en sus diócesis, vieron limitadas sus actividades. Además, desde 1833 la Santa Sede no realizó ningún nombramiento episcopal; por tanto, en 1847 ya 40 sedes estaban vacantes. Dentro de este panorama tan complejo del episcopado español, situado en el centro del debate nacional tanto por la política

62 Vicente CÁRCEL ORTí, El liberalismo... [ver n. 4], pp. 177-178. De hecho, todos estos nombres aparecen en los cargos de prócer, senador del reino u otros nombrados por el gobierno.

63 Cfr. Emilio LA PARRA, El primer liberalismo y la Iglesia, Alicante, 1985.

64 Como Pedro González Vallejo (Mallorca, 1770-1842) o Antonio Posada (Cartagena, 17681851). Cfr. Manuel Teruel Gregorio de Tejada, Obispos liberales, Lérida, 1996; Maximiliano BARrio GoZAlo, La Santa Sede... [ver n. 33]. 
religiosa liberal como por la guerra carlista, Bonel y Orbe se situó siempre como firme e incondicional defensor de la causa de Isabel II y del entendimiento con el nuevo régimen que se estaba asentando en España. Todo ello le valió, en efecto, el reconocimiento y el aprecio tanto del gobierno como de la misma soberana.

A la hora de comprender las razones que llevaron a la elección del obispo de Córdoba como prócer y senador, podemos decir que, siendo las Cortes una institución política, es evidente que el criterio de afinidad al gobierno y de lealtad a la causa isabelina fue esencial. Tres importantes historiadores han valorado la labor parlamentaria de estos prelados senadores. M. Revuelta dice que los obispos próceres:

eran, por definición, los más decididos partidarios de Isabel II, pues este fue y no otro el criterio que determinó su elección para tan honroso cargo. Eran obispos fácilmente doblegables, y atados al gobierno liberal, aunque sólo fuera por reconocimiento al honor que habían recibido. ${ }^{65}$

Cárcel Ortí, menciona un «notable influjo» que, por medio de la moderación, estos obispos ejercieron:

Cinco obispos legítimos y otros cinco intrusos fueron nombrados por la reina senadores del reino como representantes de varias provincias, tras haber jurado la Constitución de 1837. Algunos llegaron a ocupar la vicepresidencia del Senado y ejercieron notable influjo, por su prestigio personal, historial político y dotes intelectuales en las discusiones y votaciones de temas eclesiales, tratando de impedir con su moderación que prosperasen proyectos e iniciativas de los más exaltados liberales ${ }^{66}$.

Cuenca Toribio alude directamente a Bonel y Orbe como uno de los representantes que buscó caminos de conciliación con la sociedad liberal:

Otro prelado igualmente tachado de acomodaticio, Bonel y Orbe, se afanó también en horas difíciles por salvar lo que en el lenguaje romántico podría denominarse el honor de la Iglesia española. En intervenciones parlamentarias de cierto regusto sentimental aceptó el hecho consumado de la desamortización como sacrificio inevitable para un futuro de concordia. Fue éste el común sen-

65 Manuel Revuelta GonZÁlez, La exclaustración, Madrid, 2010, p. 428. Añade una referencia explícita al obispo: «el único que destacó entre estas medianías fue el obispo de Córdoba, Juan Bonel y Orbe, que pronunció en el estamento un discurso criticando la política exclaustradora».

66 Vicente Cárcel OrTí, Política... [ver n. 43], p. 419. Creemos que el autor hace una mención implícita precisamente a Bonel y Orbe, que fue vicepresidente del Senado. 
tir del denostado sector altoeclesiástico colaboracionista del nuevo régimen que continuaba así, [...] la línea moderada del progresismo clerical gaditano y veinteañista, partidaria a ultranza de las reformas, pero contraria por principio a los radicalismos ${ }^{67}$.

La presencia efectiva de Bonel y Orbe en las Cortes fue, como reconocen las fuentes, muy destacada ${ }^{68}$. Asistió con regularidad a las sesiones ${ }^{69} \mathrm{y}$ en su periodo de mayor actividad, el de 1834-1843, formó parte de 25 comisiones y fue primer vicepresidente en la legislatura $1838-1839^{70}$. Pero, por encima de todo, sobresalen sus discursos sobre variados temas: el estado del culto y clero y su dotación, los institutos religiosos y las monjas, la desamortización de los bienes eclesiásticos, el diezmo, los principios de la fe y de la religión, los derechos e independencia de la Iglesia, el papel del Papa... Entre 1834 y 1853 dirigió en total 34 alocuciones a la Cámara alta, 31 de ellas sobre temas eclesiásticos. Es, por tanto, el prelado español que más intervenciones y de mayor extensión tuvo en sede parlamentaria en este periodo decisivo de nuestra historia ${ }^{71}$.

Además de su labor tan destacada en las Cortes como prócer y senador, Bonel y Orbe también se relacionó con los diferentes gobiernos liberales que procuraron, según su ideario, la reforma de la Iglesia. En ese sentido, se situó en una línea reformista junto con una parte del episcopado del reino. En 1834 el gobierno español creó una real junta eclesiástica para la reforma del clero. Aunque Bonel y Orbe no fue contado entre sus miembros, más tarde ayudaría a este organismo en algunas de sus comisiones. Como consecuencia de la política religiosa liberal, 25 obispos dirigieron al papa Gregorio XVI una carta colectiva el 1 de octubre de 1839, que describía un cuadro deplorable de la Iglesia espa-

67 José Manuel CuenCa TORIBIo, Iglesia y poder político, en José María Jover ZaMORA (dir.), Historia de España Menéndez Pidal, t. 34, Madrid, 1981, pp. 589-640.

68 En la página web del Senado: http://www.senado.es/web/conocersenado/senadohistoria/ senado18341923/senadores/fichasenador/index.html?id1=414 (última consulta: 4-12-2017), se encuentra detallado su expediente, actividad parlamentaria e intervenciones en los Diarios.

69 Según los Diarios, solamente dos días excusó su asistencia: por enfermedad (DSC 1847-48, 20-31848 , n. 50, p. 799) y por obligaciones del ministerio (DSC $1853 / 1^{\mathrm{a}}$, 21-3-1853, n. 10, p. 107).

70 Cfr. Estadística de personal... [ver n. 17], pp. 363; y Colección de las leyes, decretos y declaraciones de las Cortes, t. 24, Madrid, 1839, pp. 588-589.

71 Según la sección histórica de la página web del Senado [ver n. 68], en el periodo 1834-1853 sólo hubo otro prelado con un número tan significativo de intervenciones: Manuel Joaquín Tarancón y Morón, con 30 discursos. El que llegaría a ser arzobispo de Sevilla y colaboraría en la elaboración del Concordato de 1851 puede ser quizás otras de esas figuras destacadas y desconocidas del episcopado decimonónico. 
ñola ${ }^{72}$. Este documento «no fue signado por otros quince prelados, seis de los cuales pueden llamarse "colaboracionistas" o adictos al Gobierno liberal» ${ }^{73}$, entre los cuales se encontraba el obispo de Córdoba. Por esta razón fueron mirados por Roma con sospecha, como pupilos en manos del gobierno español. $\mathrm{Al}$ final de la época de las regencias, ante las innumerables sedes vacantes, el obispo de Córdoba dirigió al Ministerio de Gracia y Justicia dos breves exposiciones en 1843, en las que demandaba la vuelta de todos los obispos ausentes. En ellas se situó como defensor de los prelados exiliados y abogó por la unidad del episcopado nacional después de una época de fuertes divisiones.

Durante el periodo moderado, como cabeza de los obispos españoles, trabajó por un entendimiento con el Estado y colaboró en la elaboración del Concordato de $1851^{74}$. También ejerció el cargo de presidente de la real cámara eclesiástica. Cuando durante el bienio progresista (1854-1856) Madoz llevó a cabo una nueva desamortización, el ya anciano cardenal, en calidad de primado, fue uno de los que más condenó de la política gubernamental. Así, trabajó, aunque en vano, para salvar a la Iglesia española del decreto de enajenación expedido en 1855 .

A todo ello habría que añadir su papel personal relevante en la corte de Isabel II, del que ya hemos hecho mención ${ }^{75}$. Su nombramiento como confesor real durante casi veinte años, su ascenso a la sede metropolitana de Granada en 1838, y la multitud de distinciones honoríficas evidencian el respeto, adhesión y afecto de que gozaba el prelado en el entorno real y en la misma soberana. Como arzobispo de Toledo, tuvo un importante papel de mediador entre Roma y Madrid en la llamada «cuestión de palacio» -el matrimonio entre Isabel II y el infante Francisco de Asís-; asimismo, intervino repetidamente en el asunto de la religiosa sor María Dolores y Patrocinio ${ }^{76}$. En este sentido, se puede hablar ciertamente del

72 Cfr. Vicente CÁRCEL ORTí, El primer documento colectivo del episcopado español. Carta al papa en 1839 sobre la situación nacional, en Scriptorium Victoriense, 21 (1974), pp. 152-199.

73 Vicente CÁrCEL ORTí, El liberalismo... [ver n. 4], p. 180.

74 Sin embargo, no existe ninguna mención a Bonel y Orbe en Federico SuÁrEz Verdeguer, Génesis del concordato de 1851, en Ius Canonicum, 3 (1963), pp. 65-249; ni en Juan PÉREZ ALHAMA, La Iglesia y el Estado español. Estudio bistórico-jurídico a través del concordato de 1851, Madrid, 1967.

75 En Vito-Tomás GÓmEz GARCía, El cardenal... [ver n. 1], pp. 320-323, se muestra un ejemplo de la influencia de este círculo de obispos en el ambiente cortesano.

76 Fue Bonel y Orbe quien, a instancias de la Santa Sede, visitó en 1846 a sor Patrocinio para que convenciese a Isabel de su matrimonio con su primo Francisco, cfr. Francisco MARTÍ GILABERT, Iglesia y estado en el reinado de Isabel II, Navarra, 1996, p. 175. También, el primado debió explicarse al nuncio cuando en 1849 sor Patrocinio salió de Madrid y abandonó la clausura, cfr. Franco DíAZ 
influjo relevante e incluso decisivo que ejercieron algunas figuras concretas de la jerarquía católica durante el reinado de Isabel $\mathrm{II}^{77}$.

En suma, en medio de circunstancias políticas y eclesiásticas muy adversas, Juan José Bonel y Orbe pasó como un obispo liberal moderado, tanto por su apoyo sincero a la causa de Isabel II, como por su profundo deseo de reformar la Iglesia mediante una colaboración entre la jerarquía y el Estado, contribuyendo así al progreso de la nación española. Es exponente, por tanto, de una corriente eclesial, quizá minoritaria, que abogó por el entendimiento con el nuevo régimen liberal, al menos con sus elementos menos exaltados ${ }^{78}$. El obispo acabó siendo una pieza importante en la relación de la Iglesia con los sucesivos gobiernos, tanto progresistas como moderados:

Mantuvo una intensa relación con el poder civil, y aunque en esta época la Iglesia se intenta desligar de las esferas de poder en busca de una mayor autenticidad y autonomía, él, junto con otros prelados, colaboró de una forma más o menos explícita con el nuevo régimen y simpatizó abiertamente con la ideología liberal moderada ${ }^{79}$.

Ahora bien, este juicio historiográfico general, que identifica al obispo de Córdoba con el grupo de prelados liberales y colaboracionistas con el gobierno, deberá ser cotejado con la lectura detallada de su actividad parlamentaria, en especial durante el periodo de las regencias isabelinas (1833-1843). Esta es, hasta el momento, la única producción intelectual escrita que conservamos del obispo en estos años decisivos de la política española. Sólo así podremos conocer cuál

DE CERIO, Regesto, t. 2... [ver n. 9], pp. 354-355. Más tarde, el arzobispo siguió ayudando a la religiosa, cfr. Francisco MARTÍ GILABERT, Iglesia..., p. 181.

77 «Tanto los obispos procedentes de Fernando VII como la generación posterior -los llamados obispos de Isabel II- no ejercieron en el ánimo de los monarcas una incidencia tan eficaz como la de otros grupos influyentes del momento, por ejemplo, los políticos, los generales y los nobles. No quiere decir esto que para Isabel II la voz del episcopado no tuviera su importancia. Pero más que de jerarquía o de obispos en conjunto, habría que referirse a figuras concretas, y en el reinado de Isabel II la primera alusión cae sobre su confesor, el arzobispo Claret, y sobre algunos cardenales y obispos frecuentadores asiduos de los ambientes palaciegos y cortesanos» (Vicente CÁRCEL ORTÍ, El liberalismo... [ver n. 4], p. 175).

78 Así lo reconoce Cuenca Toribio al adscribir a este prelado al grupo pequeño e influyente de eclesiásticos que «hizo posible el entendimiento mínimo para lograr la reconciliación con el mundo surgido de la revolución liberal; y, sobre todo, el que protagonizó la vertiente más importante de la restauración religiosa» (José Manuel CUENCA TORIBIO, Iglesia... [ver n. 67], p. 580).

79 Vicente CÁrcel ORTí, Bonel... [ver n. 19], p. 720. Sin embargo, tenemos que decir que, a pesar de su significativo influjo en la vida política, no tuvo mucho éxito. 
fue, de hecho, su postura real ante las reformas eclesiásticas de los gobiernos liberales ${ }^{80}$.

Por último, una visión complementaria de la figura de Bonel y Orbe la podríamos obtener desde una perspectiva romana. El nuncio Tiberi (1827-1834), en su correspondencia diplomática con Roma, califica a Bonel y Orbe como «hombre dotado de doctrina, prudencia y de óptimas costumbres» ${ }^{81}$. Más tarde, se referirá a él como «digno eclesiástico» ${ }^{82}$. A su vez, el obispo Bonel y Orbe mantuvo una intermitente correspondencia con Tiberi, de carácter más bien oficial $^{83}$. El nuncio Amat (1834-1840), por el contrario, no hace ninguna referencia significativa a Bonel y Orbe en sus comunicaciones ${ }^{84}$ ni hay constancia de ninguna correspondencia del obispo con él. Aunque es muy reveladora esta ausencia de contacto, no hemos encontrado ningún indicio del hecho de que Bonel y Orbe fuera «malquisto en un tiempo por la Santa Sede» ${ }^{85}$.

\section{CONCLUSIÓN}

Este sintético acercamiento a la figura de Juan José Bonel y Orbe nos ha permitido seguir algunos aspectos de su formación, trayectoria y actuación a lo largo de sus 75 años de existencia. En este trabajo no se ha pretendido otra cosa que poner de relieve lo que conocemos de este prelado, poco pero suficiente para asegurar su relevancia como personaje histórico que merece una mayor atención. Su biografía abarca sobre todo la primera mitad del siglo XIX y, como acabamos de comprobar, aparece ligada a muchos de los acontecimientos más importantes de la historia de la Iglesia y de España. No debemos olvidar que es en este periodo, y en especial en la década de 1833-1843, cuando explota con toda su

80 Precisamente a este trabajo invita el historiador Cárcel Ortí: «La labor parlamentaria de estos prelados merece igualmente un estudio más profundo, que excede mis actuales límites, para descubrir aspectos inéditos y quizás sorprendentes de la política eclesiástica de las Cortes y de la ideología de sus miembros» (Vicente CÁRCEL ORTí, Política ... [ver n. 43], pp. 419-420, n. 64).

81 Vicente CÁRCEl ORTí, Correspondencia diplomática del Nuncio Tiberi (1827-1834), Pamplona, 1976, p. 488: Uomo fornito di doctrina, prudenza e di ottimi costumi.

82 Vicente CÁRCEL ORTÍ, Correspondencia diplomática del Nuncio Tiberi... [ver n. 80], p. 540. También, pp. 585 y 729 .

83 Cfr. Franco Díaz DE CERIO, Regesto, t. 2... [ver n. 9], pp. 353-354.

84 Sólo hallamos un breve despacho con el juramento del obispo en Vicente CÁRCEL ORTí, Correspondencia diplomática del Nuncio Amat (1833-1840), Pamplona, 1982, p. 115.

85 José Manuel Cuenca Toribio, Sociología... [ver n. 21], p. 75. 
virulencia el conflicto entre el liberalismo -ya definitivamente consolidado- y la Iglesia en nuestro país.

Bonel y Orbe tuvo un papel destacado, en ocasiones protagonista, en algunos hitos decisivos: la guerra de la Independencia, el Trienio constitucional, la década de las regencias y el moderantismo. Asimismo, experimentó muy de cerca muchos de los grandes problemas de la Iglesia en su transición del antiguo al nuevo régimen: el regalismo, la discrecionalidad de los nombramientos episcopales, la división del episcopado, la desamortización y otras consecuencias de la política eclesiástica liberal... Su formación, su carácter y los diversos cargos que ocupó tanto dentro de la Iglesia (vicario general y gobernador, obispo, arzobispo primado y cardenal) como dentro del mundo político (prócer, senador y confesor real) le convirtieron en muchas ocasiones en una pieza eclesiástica clave ante el desarrollo de la revolución liberal en nuestro país. Aunque también es necesario reconocer que la importancia objetiva de sus numerosos cargos no siempre se correspondió con una influencia real y decisiva a nivel político o eclesial, y por ello ha podido ser considerado como una figura secundaria dentro del episcopado español decimonónico.

Por todo ello, y a la luz del itinerario biográfico de Bonel y Orbe, creemos que estudiar la biografía de este prelado supondría profundizar en la historia de las relaciones Iglesia-Estado y la respuesta que ésta dio al surgimiento del nuevo orden burgués. Todo ello contribuiría sin duda a un mejor conocimiento de la Iglesia del siglo XIX.

Si miramos con atención el itinerario biográfico de Bonel y Orbe, cabría destacar dos evoluciones muy significativas que experimentó este prelado en unos años decisivos de la transición de la Iglesia del antiguo al nuevo régimen. En primer lugar, puesto que fue una figura relevante en las relaciones de la Iglesia con el Estado, tomó gran contacto con los sucesivos elementos liberales de nuestro país. Se manifestó como un prelado reformista y abierto, decidido defensor de la causa legítima de Isabel II y de la colaboración con el liberalismo para lograr la reforma de la Iglesia. Sin embargo, ante el desarrollo de los acontecimientos, este entusiasmo inicial fue matizándose por su actitud de decepción y rechazo hacia el liberalismo más radical y progresista, del que siempre fue enemigo. Por ello, llegó a identificarse progresivamente con el programa ideológico y político de los moderados, hasta el punto de llegar a ser el primer eclesiástico de la nación en los años del moderantismo.

En segundo lugar, desde una perspectiva intraeclesial, descubrimos un muy notable desarrollo en su pensamiento. Como casi todos los sacerdotes de su época, recibió una formación marcada por el regalismo, el jansenismo y el antirro- 
manismo. A pesar de ello, los graves problemas que afectaron a la Iglesia, en especial durante la primera gran revolución liberal española, impusieron una nueva dirección. Por ese motivo, Bonel y Orbe, a causa de su defensa de los derechos de la Iglesia, se convirtió progresivamente en un ferviente defensor del Papa. Así, se acercará de manera significativa a la corriente ultramontana que se extendió por Europa precisamente durante el pontificado de Pío IX. De ambas evoluciones dan claro testimonio todos sus discursos parlamentarios ya mencionados, especialmente los pronunciados en el periodo 1834-1843. Estas intervenciones son una fuente valiosa muy poco conocida, clave para introducirse en el pensamiento y las actitudes de Bonel y Orbe. Por eso, creemos que estos discursos merecen un sosegado estudio que ahora no podemos realizar.

Este acercamiento biográfico muestra que este obispo puede ser considerado, junto a otros prelados, como un modelo paradigmático de la evolución que la Iglesia -o, al menos, una parte relevante de ella- experimentó en la primera mitad del siglo XIX en su respuesta al establecimiento y la consolidación del liberalismo en nuestro país. De este modo, algunos eclesiásticos como Bonel y Orbe respondieron a muchos de los grandes problemas que entonces se plantearon mediante un acercamiento al conservadurismo y al ultramontanismo, y pusieron así las bases para la restauración religiosa que se operó en la segunda mitad de siglo en España.

\section{REFERENCIAS BIBLIOGRÁFICAS}

Barrio Barrio, Julián, Félix Torres Amat (1772-1847), Burgos, 1978.

BARrio GOZALO, Maximiliano, El clero en la España moderna, Córdoba, 2010.

- La Santa Sede y los obispos españoles en el Trienio liberal (1820-1823), Roma, 2015.

Brusola, Vicente María y HernándeZ DE Fuentes, Niceto, Biografías de los obispos contemporáneos, prelados y demás dignidades ilustres de la Iglesia Española redactadas a vista de notas, apuntes y documentos auténticos, Madrid, 1852.

CALERO, María del Carmen, ARIAS, Inmaculada y VIÑET, Cristina, Historia de la Universidad de Granada, Granada, 1997.

CÁRCEL OrTí, Vicente, Bonel y Orbe, fuan fosé, en Gonzalo ANES y ÁLvarez DE CASTRILLÓN (dir.), Diccionario Biográfico Español, t. 8, Madrid, 2010, pp. 719-721.

- Correspondencia diplomática del Nuncio Amat (1833-1840), Pamplona, 1982.

- Correspondencia diplomática del Nuncio Tiberi (1827-1834), Pamplona, 1976.

- El liberalismo en el poder (1833-1868), en Ricardo GARCÍA-VILLOSLADA y Vicente CÁRCEL ORTÍ (dirs.), Historia de la Iglesia en España, t. 5, Madrid, 1979.

- El primer documento colectivo del episcopado español. Carta al papa en 1839 sobre la situación nacional, en Scriptorium Victoriense, 21 (1974), pp. 152-199. 
- Politica eclesial de los gobiernos liberales españoles (1830-1840), Pamplona, 1975.

Caro Cancela, Diego y Martínez López, Fernando, Bonel y Orbe, fuan fosé, en Diego Caro Cancela (dir.), Diccionario biográfico de parlamentarios de Andalucía, 1810-1869, Sevilla, 2010, pp. 249-250.

CASAS RABASA, Santiago, En el bicentenario del nacimiento de don Fosé Caixal y Estradé, obispo de Urgel, en Analecta sacra tarraconensia, 76 (2003), pp. 257-288.

ClareT, Antonio María, Cartas selectas, Madrid, 1996.

- Escritos autobiográficos, Madrid, 1981.

Closa Salinas, Francesc, El obispo Pedro Cirilo Úriz y Labayru en la encrucijada del concordato de 1851, en Hispania sacra, 67 (2015), pp. 673-715.

Colección de las leyes, decretos y declaraciones de las Cortes, t. XXVI, Madrid, 1841.

Cuenca TORIBIO, José Manuel, D. Pedro de Iguanzo y Rivero, último Primado del Antiguo Régimen, Pamplona, 1965.

- Iglesia y poder político, en José María JOver Zamora (dir.), Historia de España Menéndez Pidal, t. 34, Madrid, 1981, pp. 589-640.

- Sociedad y clero en la España del siglo XIX, Córdoba, 1980.

- Sociología del episcopado español e hispanoamericano (1789-1985), Madrid, 1986.

DE AlCÁNTARa RodríGUEZ, José Pedro, Oración fúnebre del Emmo. Señor Don fuan fosé Bonel y Orbe, Madrid, 1858.

De Pobladura, Melchor, Semblanza del cardenal Pedro de Inguanzo, Arzobispo de Toledo. Escrita por 7. Fernández Cortina, en Hispania Sacra, 5 (1958), pp. 327-338.

DE VARGAS, Antonio R., Instrucción sobre los Seminarios eclesiásticos llamados conciliares, y con especialidad sobre el de S. Sebastián de la ciudad de Málaga, Montevideo, 1844.

Diario de las sesiones de Cortes. Estamento de ilustres Próceres. Legislaturas 1834-1836, Madrid, ${ }^{2} 1883$.

Diario de las sesiones de Cortes. Senado. Legislaturas 1837-1853, Madrid, ${ }^{2} 1884-1895$.

DíAZ DE CERIO, Franco, El Cardenal Ceferino González, O. P. (1831-1894), en Pensamiento, 20 (1964), pp. 27-70.

- Regesto de la correspondencia de los obispos de España en el siglo XIX con los nuncios, Ciudad del Vaticano, 1984.

- Un cardenal, filósofo de la historia. Fr. Zeferino González, O.P. (1831-1894), Roma, 1969.

Dufour, Gérard, De la Ilustración al Liberalismo. El clero jansenista, en Armando ALBEROLA ROMÁ y Joseph PÉREZ (coords.), España y América entre la Ilustración y el liberalismo, Alicante-Madrid, 1993, pp. 57-68.

Estadística de personal y vicisitudes de las Cortes y de los Ministerios de España. Desde el 29 de septiembre de 1833, en que falleció el Rey D. Fernando VII, hasta el 11 de septiembre de 1858, en que se disolvió el Congreso de los Diputados, Madrid, 1858.

GARCÍA-CUEVAS VENTURA, José, El cabildo catedralicio cordobés desde la revolución a la Restauración (1788-1882), Córdoba, 1996.

GIL Novales, Alberto, Diccionario biográfico de España (1808-1833), Madrid, 2010.

GómeZ GARCÍA, Vito-Tomás, El cardenal fr. Manuel García y Gil, O. P. Obispo de Badajoz y arzobispo de Zaragoza (1802-1881), Valencia, 1990.

GoÑi GaZTAmbide, José, El obispo de Málaga, Cañedo, en el Trienio Constitucional, en Hispania Sacra, 32 (1980), pp. 193-227. 


\section{GONZALO BARBED MARTÍN}

GUERRERo CAROt, Francisco José, Un cruzado contra el Liberalismo. Aguilar y Serrat (Manlleu 1826-Segorbe 1899), obispo de Segorbe, Segorbe, 2013.

GuTIÉRrEZ GARCÍA-BraZALES, Manuel, El cardenal Inguanzo (1824-1836), en Cuadernos de bistoria contemporánea, 13 (1991), pp. 9-24.

Herrera Mesa, Pedro Pablo, Escritos pastorales de los obispos de Córdoba (1627-1857), Córdoba, 2004.

http://www.adurcal.com/enlaces/mancomunidad/titulos/bonel/jjbonelorbe.htm (última consulta: $21-05-2018)$.

http://www.senado.es/web/conocersenado/senadohistoria/senado18341923/Estatuto1834/ index.html (última consulta: 4-12-2017).

KANTOROWICZ, Ernst H., Los dos cuerpos del rey, Madrid, 1985.

LA PARRA, Emilio, El primer liberalismo y la Iglesia, Alicante, 1985.

MARTí GILABERT, Francisco, Iglesia y estado en el reinado de Isabel II, Navarra, 1996.

MARTÍN HERNÁNDEZ, Francisco, La formación del clero en los siglos XVII y XVIII, en Ricardo García-Villoslada y Antonio MESTRE SANCHÍs (dirs.), Historia de la Iglesia en España, t. 4, Madrid, 1979 , pp. 556-582.

MARTÍNEZ AlbiaCH, Alfredo, Fe y razón entre dos concordatos (1753-1851), en Melquíades ANDRÉS MARTíNEZ (dir.), Historia de la teología española, t. 2, Madrid, 1987, pp. 443-481.

Martínez Lumbreras, Francisco, Una fundación granadina. Historia del Real Colegio de S. Bartolomé y Santiago, Granada, 1915.

MENÉndeZ Pelayo, Marcelino, Historia de los heterodoxos españoles, Madrid, 2011.

MESTRE SANCHÍs, Antonio, El jansenismo español de los siglos XVII y XVIII, en Augustin FLICHE y Victor MARTIN (dirs.), Historia de la Iglesia, t. 22, Valencia, 1976, pp. 563-585.

Mondéjar Cumpián, Francisco, Obispos de la Iglesia de Málaga, Córdoba, 1998.

Montanos Ferrín, Emma y SánCHEZ-ArCilla Bernal, José, Historia del derecho y de las instituciones, Madrid, 1991.

Nieto Cumplido (coord.), Manuel, Historia de las diócesis españolas, t. 8. Iglesias de Córdoba y Faén, Madrid-Córdoba, 2003.

ODRIOZOLA ARgOS, Francisco, Zuan Fosé Bonel y Orbe. Un obispo preconizado para la diócesis de Santander, en Altamira, 69 (2006), pp. 107-118.

OrIVE, Aniceto, Bonel y Orbe, Fuan Fosé, en Quintín AldEA, Tomás Marín y José VIVEs, Diccionario de Historia Eclesiástica de España, t. 1, Madrid, 1972, p. 273.

Osorio PÉrez, María José, Historia del Real Colegio de San Bartolomé y Santiago, Granada, 1987.

PÉREZ AlHAMA, Juan, La Iglesia y el Estado español. Estudio histórico-jurídico a través del concordato de 1851, Madrid, 1967.

PÉREZ, Esteban José, Oración fúnebre que a la inmortal memoria del Emmo. Señor Don fuan Fosé Bonel y Orbe, Madrid, 1857.

PRODI, Paolo, El soberano pontifice. Un cuerpo en dos almas, Madrid, 2010.

Relación de los méritos, grados y exercicios literarios del doctor don fuan Fosé Bonel y Orbe. Examinador Sinodal de Granada y Guadix, 1814.

Revuelta GonZÁleZ, Manuel, La exclaustración, Madrid, 2010.

- Política religiosa de los liberales en el siglo XIX, Madrid, 1973. 
RitZler, Remigius y Sefrin, Pirminus, Hierarchia Catbolica medii et recentiores aevi, t. 7, Patavii, 1968.

Ritzler, Remigius y Sefrin, Pirminus, Hierarchia Catholica medii et recentiores aevi, t. 8, Patavii, 1978.

RUIZ GaRCía, Félix, Patriarcado de Indias y Vicariato General Castrense, en Revista Española de Derecho Canónico, 23 (1967), pp. 449-471.

SÁNCHEZ AGESTA, Luis, Historia del constitucionalismo español, Madrid, 1984.

SANZ DE DiEGO, Rafael María, Medio siglo de relaciones Iglesia-estado. El cardenal Antolín Monescillo y Viso (1811-1897), Madrid, 1979.

SuÁREZ Verdeguer, Federico, Génesis del concordato de 1851, en Ius Canonicum, 3 (1963), pp. $65-249$.

Teruel Gregorio de Tejada, Manuel, Obispos liberales, Lérida, 1996. 
